\title{
10
}

\section{Resources and resourcefulness: Gender, human rights and resilience in artisanal mining towns of eastern Congo}

\author{
Rachel Perks, Jocelyn Kelly, Stacie Constantian \\ and Phuong Pham
}

Few things evoke reactions as passionate as issues surrounding gender, conflict and mining in the eastern Democratic Republic of Congo (DRC). At once reviled by international advocacy organisations and celebrated by local communities, mining is viewed as both the scourge and the saviour of a region wrecked by decades of violence. Studies have reported on human rights as well as on the status of women in the DRC, and although some examine the link between mining and sex-based violence, little research explores the gender dimensions of artisanal and small-scale mining (ASM). The research in this chapter was framed by questions such as: Do men and women face similar difficulties when seeking to gain employment in mining? Are they afforded similar opportunities once they have secured access into ASM? What are the most prevalent social, economic and health impacts experienced by individuals. Are these impacts gendered? A human rights-based approach informed the range of issues examined, such as gender, militarisation of the extraction process and free and equal participation in political, judicial and economic systems. By speaking with a wide variety of actors who live and work within these communities, we attempted to identify issues that are 
common to mining-affected areas. The experiences of both women and men were examined, but a particular focus remained on understanding women's experiences in mining towns. Hence, the research was ultimately guided by the hypothesis that by understanding issues related to safety, security and economic opportunities for women, significant gains in both economic and social development in the eastern DRC could be achieved.

The Harvard Humanitarian Initiative in collaboration with the World Bank conducted two phases of research: Phase 1 (qualitative), followed by Phase 2 (quantitative). Research was conducted in North and South Kivu provinces, two of the most conflict-affected areas of the DRC. Phase 1 took place in 2012, with the aim to elicit experiences of male and female miners, using a human rights framework of inquiry developed specifically for the project. Five key findings resulted from the qualitative research in Phase 1, which then informed the quantitative, population-based survey in Phase 2. These focused on gender-based violence, discrimination, right to health, access to justice and right to participation. Although women were vital actors in mining communities and filled many roles, they were also among the most vulnerable to sexual and economic predation. Sexual exploitation was described as commonplace in mining towns, and many women spoke about engaging in transactional sex out of desperation. It is important to acknowledge the practice of discrimination, because mining jobs are theoretically open to everyone; however, actually acquiring work was dictated by one's ability to pay for access to the mines. Women and other vulnerable populations were generally relegated to marginal support roles in mining towns. Right to health is important because is it crucial to a woman's well-being. Health problems were summarised into three categories: poor labour conditions; poor structure of mining tunnels; and public health problems, such as poor hygiene and high levels of infectious diseases. For the majority of participants, access to justice was a demand arising from the sufferance of human rights violations. Those most vulnerable to human rights abuses, such as orphans, widows, sex workers and displaced persons, were also those least able to access traditional and formal justice mechanisms. Right to participation in a situation of highly restricted access to political participation and widespread discrimination was crucial.

Phase 2 used a quantitative survey to examine the scope of human rights issues emerging from Phase 1 in select mining towns. The survey results affirmed the human rights issues raised in Phase 1, and provided some indications of the frequencies of experience within the total sampled 
mining populations. ${ }^{1}$ The survey was a cross-sectional study from three territories (Kalehe, Mwenga and Walungu) in the South Kivu Province of the eastern DRC. Sites were sampled from a comprehensive list of artisanal mining sites, compiled by the International Peace Information Service. This list documented 800 mining sites and 85 trading centres, with information about armed groups' presence and involvement, and the scale of the mining activity in 2012 and 2013. A total of 998 surveys were collected for this project: 357 individuals were female and 641 individuals were male. The next section outlines selected research findings, combining both qualitative and quantitative data from Phases 1 and 2 .

\section{Women, mining and conflict in the DRC}

ASM and its relationship to armed conflict in the eastern provinces of the DRC has been has been vividly described, researched and discussed. The wars in the mid-1990s accelerated the disintegration of agricultural economies that had begun during structural adjustment in the early 1980s. Active hostilities stretched into decades of insecurity, and the resulting displacement, crop viruses, threat of violence and danger of looting and predation by armed groups shaped entirely new economic and social systems. ASM assumed a more prominent role in rural economic life. In the DRC, some authors have written of the causes and consequences of 'deagrarianisation' - the transition away from agriculture towards other rural livelihoods - with respect to the proliferation of ASM (Perks 2011; Smith 2011; Geenen 2012; Kelly 2014). Important to note from these prior research findings is that the manner of transformation of the rural economic landscape in the DRC, and the role played by mining in this transformation, mirrors the experiences of other mineral-rich environments. Also important to highlight are the varying degrees of political stability under which 'deagrarianisation' and ASM proliferated in these environments: from politically stable Ghana (Banchirigah 2008), Burkina Faso (Luning 2008) and Tanzania (Bryceson and Jønsson 2010), to outright civil destabilisation in Sierra Leone (Maconachie and Binns 2010). ${ }^{2}$ Such varied political landscapes under which ASM has proliferated

1 For purposes of brevity, this chapter concentrates on research results that inform the first three findings. Those interested in seeing the full results can refer to the full report from the World Bank (2015a), titled 'Resources and Resourcefulness: Gender, Conflict, and Artisanal Mining Communities in Eastern Democratic Republic of the Congo'.

2 For an overview, see Hilson (2011). 
across the subcontinent in the last 30 years beg the question for the DRC as to the extent to which the proliferation of ASM can be best, or perhaps solely, understood from a prism of conflict. Such a reframing of our understanding of ASM might further lead to new methods of inquiry with respect to the social, environmental and economic externalities associated with ASM today. Are human rights issues associated with ASM in the eastern DRC best understood as a product of instability and armed conflict? Or is there a more complex landscape of contributing factors? These are important issues to raise at the outset, for the framing of the cause and consequences of ASM in the eastern DRC has often been associated most vividly with conflict, despite, as suggested, evidence from other environments in sub-Saharan Africa that shows ASM proliferation to have significant roots tied to general economic decline in rural areas since the 1980s, and poor government regulation of ASM equally since that period.

\section{Unpacking myths and exploring realities of human rights in the mines}

The nature of ASM in the DRC, given its illegality and the diversity of jobs and types of minerals extracted, has been historically difficult for many in the international community to comprehend, resulting in a wide range of potentially destructive narratives being applied to a remarkably diverse and vibrant local economy.

A prevalent narrative surrounding ASM in the eastern DRC is that the wealth generated from mining fuels the ongoing conflict in the eastern DRC and, as a result, exacerbates the conflict-related abuse of women. Advocacy narratives have named so-called 'conflict minerals' as a main driver of insecurity, and linked it with rape as a weapon of war. However, several academic pieces have refuted this simplistic narrative as follows: this prominent storyline offers an over-simplified version of reality, in which non-state or rebel armies exercise control over mines, and every worker is essentially subject to slavery. Coercion is typified as the manner in which women end up in mines or mining towns; thus, much of the employment is coerced or involuntary. Several scholars have called into question this narrative's simplicity (Geenen and Custers 2010; Autesserre 2012; Geenen 2012; Seay 2012; Bashwira et al. 2014; Perks 2013; Spittaels and Hilgert 2013), the results of which are discussed in the next section. 


\section{Results: Why people stopped farming}

The fear of sexual violence during conflict was specifically cited as a reason why people ceased farming and entered mines instead. Women in the mining town of Nzibera described how rape in particular affected farming: 'If people went to their farm, they can get raped or even gang raped, because we think if we say "no," they will kill us'. A young woman in Nzibera explained, 'There is lots of hunger here. But if you have been raped on your farm, you will never return, and the farm will just die'.

In Nyabibwe, women described insecurity and violence as an ongoing deterrent to resuming agricultural activities:

During the war things changed, if you tried to go to the farm they would rape you, take your things, the biggest consequence of war is that it locked people in, there was no freedom to move to different areas to sell your goods or to look for work ... After the big war still things remain difficult, people tell you there is peace and that it is OK to go to the farm, but when you go, if they don't kill you they will rape you.

\section{Motivations for entering the mines}

Phase 1 results revealed a general decline in the viability of agriculture as a sole source of income due to the conflict and general insecurity following the war. These factors seemed to frame the historical motivation for entry into mining, particularly with older respondents. The quantitative survey examined the drivers of migration to mining towns in more detail. Mining populations participating in the survey were highly migratory: here, 48 per cent of women and 38 per cent of men stated that the town they currently worked in was not their place of origin $(n=412)$. Women's rate of migration was statistically higher than men's (at $\mathrm{p}<0.05$ ). Individuals who identified themselves as migrants were asked why they sought work in mining towns. People were asked about their reasons for moving to mining towns, and were allowed to select more than one option. The results show that 55 per cent of respondents stated that there was no work in their communities of origin; almost as many stated that they sought work in mining because there were no services in the areas from where they came. Women were more likely than men to cite lack of money or employment as a driver to migrate, whereas men were more likely to cite lack of services as a motivation. One-third of women and men stated that lack of food drove them to migrate to mining towns. 
Violence and insecurity were less commonly cited as drivers to migrate than economic reasons-15.7 per cent of respondents stated these were the factors in their decision-making, with relatively little difference between men and women. One of the least cited reasons for migration was direct displacement by armed groups. These results suggest that the conflict may have created the conditions by which mining became an appealing industry, but direct conflict-related considerations were less important than economic drivers.

\section{Framing the results along the human rights framework}

\section{Sexual and gender-based violence: The blurred lines between sex work and sexual exploitation}

Many women spoke about engaging in transactional sex out of desperation-a profession that placed them at an increased risk of experiencing rape and other forms of abuse. Sex workers were often migratory and without social or financial support. Sexual predation by armed men was also described as a concern, although it was generally less pressing than the everyday violence and abuse that women suffered as a result of living in mining towns.

The qualitative research illustrated how running a restaurant, engaging in sex work and transporting materials are by no means mutually exclusive roles. Instead, one leads to, or requires, doing another. Many women spoke about having to transact sex simply to survive. Often, this is because they do not have a husband or other male relatives to bring an income home, and are forced to fend for themselves. They went on to describe how trading sexual favours was a prerequisite for gaining access to small jobs in mining towns:

People also force women to have sex with them by saying that if you don't sleep with me you won't get to keep carrying bags ... Women do prostitution so that they can get other work. You are selling yourself, tiring yourself to get some money for your children.

Women described the close links between economic and sexual exploitation: how they aren't paid or are underpaid for the work they do; are sexually harassed or raped while working; are physically beaten; and are forced to perform sexual favours in order to get clients or employment. 
Those women who speak out about their exploitation are forced out of the area under threat. As a young sex worker in Nyabibwe said simply, 'If you refuse them (sexually), they will tell you if you return again to the area they will kill you'.

All actors interviewed in the qualitative phase of this project emphasised that sex work was widespread and commonplace in mining contexts. As one man said, 'The soko [market] of the prostitutes is the mining quarry'. Exchanging sex for goods is one of the only ways women can provide for themselves and their families. Poverty was described as a defining driver of prostitution. Even wives of miners spoke frankly about the temptations for their husbands: 'Yes—it [prostitution] exists because of poverty. Around the mines, women prostitute themselves to get money that the miners give them and because otherwise they wouldn't have anything to eat'.

In many sites, sex workers came from other areas and had to build a life without the benefit of social networks or peer support in their new environment. Women may also migrate from mining town to mining town, looking for a better situation. Miners emphasised the transitory nature of the work, saying, 'There are also many prostitutes from all over, Uvira, Bukavu, they here when there is action here. They call their friends, everyone comes, we don't even know their faces'.

Women engaging in sex work may face stigma and social rejection in their home communities when they return, particularly if they have children out of wedlock. This means that once a woman begins to trade sex in mining towns, it can be difficult for her to leave this line of work. Women may find themselves caught in a cycle of travelling to look for work in places with the most productive mines, where men have disposable income.

The 'choice' to engage in sex work is made against a backdrop of desperation, violence and coercion. This reality means that respondents in the research saw sex work and sexual violence as closely linked. Participants described sexual violence as forcing a woman to have sex against her will, but they also described other forms of this abuse, including men refusing to pay for sexual services. As one miner described, 'The meaning of rape is to take someone by force and even if you haven't already agreed to do it you make them have sex with you, this is a common thing in our area'. Women transporters reinforced this, saying, 'When a man is drunk he can also rape a woman without hav[ing] a conversation, and 
even if it looks like prostitution, it is rape. This happens a lot of time to prostitutes'. One young miner simply stated, 'Ya kila qualite na aina iko hapa nyabibwe [There is sexual violence of every quality and kind here in Nyabibwe]. When God built the mine here he knew that rape would be there as well with the mine'.

Men also said that women could be at fault for their own rape, either by dressing provocatively or by getting themselves into dangerous situations. The responsibility for avoiding violence was put squarely on women's shoulders. As one young miner explained:

How can we fight rape? It is a personal decision. You [a woman] must protect yourself, if you don't expose yourself in front of a man they cannot rape you ... rape is here is because the women expose themselves and comport themselves in a certain way.

These attitudes illustrate the gross inequality that women face. Excluded from power structures and decision-making structures, the only thing they are perceived to be responsible for is the violence that is perpetrated against them. Often, women made differences in sexual violence from civilians versus armed men. Soldiers are described as engaging in forms of militarised rape, which have become common as a result of conflict in the DRC. As miners in Nyabibwe noted, 'Soldiers are the ones who are used to raping women ... but it is usually driven by a gun ... But it is not that common among us civilians'. As women transporters described, 'Is it here-yes, when there is war. Ntaganda, Nkunda—their soldiers rape IDPs [internally displaced persons], then others keep the practice going'. The leader of the sex workers' association in Nyabibwe said, 'Soldiers they usually don't pay for sex, sometimes demobilised soldiers as well, but even miners themselves, many don't pay for sex afterwards'.

The experiences of sexual and gender-based violence (SGBV) were explored in order to measure the extent of trading sex for basic goods and services. It became clear that money was the commodity that was most often traded for sex: 38.1 per cent of women reported this. Also common was the need for women to trade sex for protection, with one in five women (20.4 per cent) reporting this experience. Protection, as described in Phase 1, could include being granted access to safe working conditions or protection from violence from other actors. In contrast, men's rates of exchanging sex for any good or service (money, protection 
or work) was quite stable, at roughly 6 per cent. This implies that there is a small but stable population of men among those sampled who engage in transactional sex.

Active sex work in mining towns is, at least in part, influenced by the transient nature of the work, and the fact that men often come to mining areas without a spouse or partner. Women may come to mining towns expecting to engage in other kinds of work, such as trading or selling of small goods, but will find themselves then compelled to engage in regular sex work. One-fifth of all women (20.1 per cent) working in mining towns identified themselves as sex workers, whereas only 1.3 per cent of men did so. Of those who reported engaging in sex work, 93 per cent of women and 100 per cent of men say they work for themselves, rather than for a boss or association. These findings suggest that although sex work is a common profession for women, those engaging in it are not controlled by an outside entity.

Twenty-eight women said they were sex workers, but had not planned on getting into this work when seeking work in mining. Of these women, three-quarters said they were compelled to do sex work because of poverty, and another 18 per cent said that sex work was more profitable than the work they had originally intended to do. One-third of women said they went into sex work because they were not able to get other jobs, and 18 per cent said they did sex work to gain access to other types of work.

Above and beyond the varied forms of SGBV, women surveyed in Phase 2 reported incidences of harassment. For instance, one-third of women stated that they had been harassed by men in the mines. Of these women, 89 per cent said they had experienced harassment in the past 12 months. Sex workers had 10 times greater odds of reporting harassment than nonsex workers (odds ratio $=10.6, \mathrm{p}<0.001$ ). Only 7 per cent of women stated that they had ever discussed this harassment or discrimination with others; although, encouragingly, almost 30 per cent of women stated that associations might be able to help with these kinds of problems. When asked what kind of help might be offered, 82 per cent of women said that these organisations could provide advice, and 18 per cent said that these organisations would be able to speak to authorities on their behalf. We return to the pivotal role to be played by forms of social organisation later in this section. 


\section{Discrimination}

Interestingly, almost five times more men than women reported having ever been denied a job in the mines that they wanted to have. It may be that men aspire to have more lucrative or competitive jobs, whereas women may not seek these positions. When women gave answers about which jobs they were denied, they were more likely (in the open-ended question format) to state that they had been denied access to the mining area as a whole, rather than stating they were denied a specific job. Furthermore, 13 per cent of women surveyed in Phase 2 reported that they had been told, once having secured a job, that they could not earn the same amount of money as men. Finally, 16 per cent of women surveyed in Phase 2 reported that they had to turn down jobs in the mines because of problems at home. The most common problem cited was caring for children (65.5 per cent), followed by caring for others ( 10.3 per cent).

Outright denial of jobs to women in the mines can, in part, be explained by attitudes towards women's participation in mines, and lack of general knowledge about their rights under the Mining Code, its accompanying regulations and broader laws on women's right to work. Phase 1 highlighted a number of misconceptions about mining laws and regulations. Therefore, Phase 2 incorporated a module dedicated to knowledge about and access to information about mining regulations and laws in the survey instrument. The 'Knowledge, Attitudes and Practices' module attempted to assess knowledge, not only about the existence of mining-related policies, but also about perceptions around these policies. Only 26 per cent of women and 40 per cent of men reported that they knew there was a mining code in the DRC. Seventy per cent of women and 94 per cent of men stated that they would like to know more about it.

One common misconception was that women were not allowed to work directly in mining-related jobs. This may be related to a poor understanding of the policy that bans pregnant women from undertaking hard labour. Data supports the fact that this is a widely held assumption. Only 17 per cent of women and 20 per cent of men thought that women had the right to work as miners. Interestingly, when the survey asked the same question about women's right to work as mineral buyers or traders, 60 per cent of women and 65 per cent of men stated that they did have this right. Therefore, misconceptions about the right to work in mining may, at least in part, be related to ideas about women doing physically taxing work. 
The Congolese mining code also allows children over 15 years of age to work in mining contexts, as long as the work is not physically dangerous. However, because of intense international advocacy about the dangers of child labour in mining towns, there is great sensitivity about admitting that children work in these areas. Although the practice is widespread and children often act as porters, washers, vendors and miners, this is often hidden from visitors for fear that mining activities may be suspended if child labour is discovered. This is reflected in the survey responses. Individuals were asked if children were allowed to work in mining towns, if the work was not physically hazardous. Seventeen per cent of women and 20 per cent of men said that children did not have the right to do this kind of work.

\section{Right to health}

Working in mining towns brings with it risks for a number of health hazards - from physical injury associated with hazardous physical work, to sexually transmitted infections because of high levels of transactional sex. Health problems may be compounded by limited access to health care in these areas, or limited ability to pay for services that do exist. In the qualitative survey of Phase 1, health problems in mining towns were broken down into three categories by participants: (i) poor labour conditions; (ii) poor structure of mining tunnels; (iii) public health problems such as poor hygiene and high levels of infectious disease. The scarcity of public health resources in mining areas, such as toilets, clean water supply, waste systems and primary care facilities, combined with close-quartered living conditions leads to high prevalence of diarrhoea, tuberculosis, respiratory infections, malnutrition and malaria. These problems are consistent across all the sites visited. Sexually transmitted infections, including HIV/AIDS are also described as significant problems, although people have such poor access to health care that these conditions are often not officially diagnosed. The head nurse in Mulamba describes the biggest health issues facing his community:

There is a lot of HIV/AIDS; poverty leads women to exchange sex. There are also sanitary problems and many accidents and blunt trauma from landslides and rockfalls. There is tuberculosis in the mines. Close to the mines, we see cholera, amoebas, diarrhea, measles and typhoid. 
Lack of access to health care due to financial or geographical obstacles exacerbates these issues. Many participants explain how pursuing health care is not an easy choice. Miners in Mulamba illustrate the sacrifice it often takes to get medical treatment:

When people need care, they are transported to the nearest health centre. They must sell their fields or goats to pay for health care. They can't make enough to pay for care from the mines.

The head nurse in Mulamba goes even further, saying many must choose between eating and going to the health centre, and that such barriers to health services lead many to put their faith in prayer or magic over health care:

You will see that in one family, if someone falls sick, the little they make is not enough to pay [for health care]. Many people die because their family decides to eat rather than to pay the clinic fees for one person. This is because of the kind of poverty we live in. People say that health problems are a result of witchcraft. They pray instead of getting care.

Phase 2 used the quantitative survey instrument to delve deeper into frequencies of health issues. Fifty per cent of women and 40 per cent of men reported having a medical issue in the past year. Encouragingly, of those individuals reporting a problem, 78 per cent of women and 70 per cent of men said they accessed care for this problem.

A majority of women (71 per cent) and men (88 per cent) said that the care they received was adequate. However, a notable percentage of women (27 per cent) and men (10 per cent) said that the care they received was not adequate. It is striking that women were three times more likely than their male counterparts to say they received poor care at a health facility (as defined by the participants' perception).

Fourteen per cent of women and 7 per cent of men stated that they had been denied medical care at least once in their lives, with women twice as likely as men to experience this problem. When asked about the reasons why they were denied health care, the vast majority of both women (84 per cent) and men (81 per cent) stated that they could not pay for health care services. The second-most commonly cited reason was that the clinic did not know how to treat their condition; this reason was cited by 10 per cent of women and 7 per cent of men. One in four women and men said that they had taken out a loan to pay for medical care. 
When one disaggregates the experience of being denied health care by profession, clear differences emerge. Those in less prestigious jobs are more likely to report denial of care. Miners, food vendors and sex workers are the most likely to report this experience, whereas those in positions of power are much less likely to be denied care. Those who were most likely to report being denied access to health care were those who also reported experiencing a health problem in the past year. These results speak to the fact that those in the least privileged jobs are the most likely to have health issues.

\section{Discussion}

The popular advocacy narrative surrounding ASM in the eastern DRCthat the wealth generated from mining fuels the ongoing conflict and, as a result, exacerbates the conflict-related abuse of women-has been questioned by a number of scholars, who argue that over-simplification has led to misguided policies and a lack of understanding about the true issues facing women (and men) in the mining areas of the eastern DRC (Pact Inc. 2010; Hayes and Perks 2012; Seay 2012, 2014; Kelly et al. 2014a, Kelly et al. 2014b). The findings of this project emphasise that the conditions and dynamics in which people work in ASM sites are more complex, but there are also concrete points for positive change.

The respondents in both phases of this project were highly migratory populations with low levels of education. Women cited a lack of money or employment as reasons for migrating, whereas men moved most often because they lacked access to services in the areas from where they came. Women who seek work in mining towns are often the sole income earners in the family, either due to the loss of husbands or male family members through conflict, or due to the failure of their traditional income earning strategies (Hayes and Perks 2012). The higher rates of women's migration to unfamiliar towns can also bring a number of vulnerabilities, including lack of access to social support groups and lack of access to, and knowledge of, goods and services. The least reported reason for migration was displacement by an armed group, which highlights how economic and development opportunities were a greater motivator for the respondents sampled than conflict insecurity-a finding that is consistent with other recent studies (Geenen 2012). 
This report also highlights how acts of discrimination and exploitation in mining areas can range from the subtle-such as a lack of representation among mining authorities, political disenfranchisement, exposure to occupational health hazards without proper access to health services and illegal taxation - to the extreme-such as sexual violence, child labour and debt bondage. Although the latter abuses often receive the most attention, the former are perhaps the most pervasive. Consider the findings from a 2014 US Agency for International Development (USAID) survey in artisanal mining towns in northeastern DRC: although labour trafficking, forced marriage, and debt bondage were reported by survey participants, these abuses were relatively rare and many of the perpetrators were described as family members, mining bosses, other miners or government officials, as opposed to armed actors from a particular group (Kelly et al. 2014a). The same report details abuses such as usurious lending, work without pay and predatory taxation. These practices were, however, undertaken mostly by civilian authorities rather than armed actors (ibid.). These types of exploitation also emerge in the findings from the present report, confirming prior research results cited herein.

Although women are vital actors in mining communities and fill a variety of roles, they are also among the most vulnerable to sexual and economic predation. The more profitable jobs are, more often than not, kept for men. Women are paid less than men for the same amount of work or level of effort, and are excluded from high-level conversations that ultimately dictate their circumstances (Hayes and Perks 2012; Kelly et al. 2014a). Unfortunately, such practices are not exclusive to the DRC alone, as described by Eftimie et al. (2012), Lahiri-Dutt and Macintyre (2006), and Hinton et al. (2003) in other ASM contexts across the globe.

This report details how gendered employment patterns emerge in mining towns. The job of miner was almost exclusively filled by men, whereas the vast majority of women worked in support roles, such as selling food or engaging in transactional sex. Past research also found that women are excluded from the highest-paying jobs, with many relegated to occupations such as sorting, gathering, washing, cooking, selling goods and/or engaging in transactional sex (Hayes 2008; Hayes and Perks 2012). No women worked as chefs d'equipe, comptoirs or PNGs, and only eight men reported being sex workers. Looking at the marital background of men and women who seek work in mining towns highlights a notable difference: whereas most men working in mining towns are single or married, a very high proportion of women therein reported being 
widowed or divorced. These findings suggest that women who have lost the support of a male relative, either through death or separation, may be forced to seek work in mining towns in order to survive. As noted by Hilson (2009), mining towns can provide opportunities for employment for traditionally marginalised populations. The jobs that are available to these vulnerable groups, however, are often low paying and exploitative.

Results from this work also highlight the overly simplistic nature of the narrative of 'rape as a weapon of war'. Women in ASM communities navigate a complex backdrop of sexual abuse. Sex is frequently a necessary component of employment in ASM, either as a profession in and of itself, or as a requirement in order to access other work opportunities or security. Women deal with myriad challenges, sometimes in the form of men failing to pay after sex or forcing the woman to have sex even if a price has not yet been negotiated. In focus groups, women reported sexual harassment, rape and forced performance of sexual favours, and the USAID report found that 7.1 per cent of the female survey participants had experienced forced sex within the past year (Kelly 2014). Responses to the USAID survey highlight the additional vulnerability implicit in this kind of transactional sex work, as women who reported having engaged in sex work were significantly more likely to also report sexual violence (ibid.). Bashwira et al. (2014) and Mahy (2012) support these findings, reporting on the complex dynamics between sex, employment and power in ASM communities.

Exclusion for political processes and entrenched discrimination were described as the norm in the communities visited for Phase 1. Vulnerable groups, including women, the elderly, the poor and landless, children and the handicapped (to name a few), were absent from political decisionmaking. Instead, participants stated that power resides in the hands of a few individuals. Marginalised groups described their efforts at selforganising into associations in an attempt to gain a sense of self-agency. However, they lack the financial means, human capacity and political influence to make lasting impacts.

The reasons behind marginalisation of women in particular are myriad. However, they seem to rest principally on three mutually reinforcing axes: cultural norms, altered family structure (resulting from decades of war and destruction) and education. Despite women's rise in the public work domain, many traditional and socially entrenched patriarchal beliefs continue to prevent women from engaging in meaningful, productive employment in the mines. The burden of the female single wage earner 
becomes even starker, as the most vulnerable women face higher rates of sexual predation than their married female counterparts. This culture has further retained and made remarkable use of common superstitions that perpetuate the belief that women working in mines are a form of bad luck. Hayes and Perks (2012) provide the example of a prevalent belief held among miners in Orientale and Katanga provinces: if a woman enters a mine, the minerals will vanish. These norms and taboos are perpetuated by a lack of education regarding mining laws and codes. Kelly et al. (2014b) provide the example of an article within the 2002 Mining Code for the DRC, dictating that pregnant women cannot engage in hazardous or heavy labour. This specific mining code article has enjoyed sweeping misinterpretation across the mines in the DRC, in order to prevent women from engaging in any mining activity. As shown in the report, people are often ignorant of the rights they have under national and international law. In fact, ignorance and misconceptions about mining laws and regulations are widespread. The continued marginalisation and exploitation of women and children is but one expression of this ignorance.

This work particularly investigates patterns of discrimination and political exclusion. Women were more likely to be denied access to the mining area, overall. Notably, there was a widespread perception that women were not allowed to work as miners or in other physically taxing jobs. These misconceptions do not lead to the total exclusion of women and children from mining areas but, rather, to their marginalisation to low paying support jobs.

The lack of structures to ensure fair practices and to promote justice served to reinforce a culture of predation on women-fostering an ethos of both cultural and judicial impunity. As highlighted by an outside scholar and by an SGBV expert during a feedback session on the report results in Washington, DC, the general erosion of state institutions has contributed enormously to the abuse of women-economically, physically and sexually - both in the mining and non-mining areas of the eastern DRC (see World Bank 2015b). Putting aside the question of whether the culture of impunity is more acute in mining versus nonmining areas, it is important to recall the nature of these extractive environments - by and large remote, isolated geographic spaces where alcohol and drug consumption is prevalent (Pact Inc. 2010). Those most vulnerable to human rights abuses, such as orphans, widows, sex workers and displaced persons, are also those least able to access traditional and formal justice mechanisms. It has emerged clearly from 
this feedback session that rebuilding state institutions needs to be placed front and centre in the fight to promote women's rights in these settings. In viewing SGBV as an expression of a much wider societal breakdown, one begins to see how multifaceted human rights issues are in mining areas, by consequence requiring a holistic, multisectoral approach towards rebuilding individuals, families and communities at large.

One could consider, for example, the health consequences of SGBV alone to understand the need for a multisectoral approach. Participants in the research project spoke particularly about HIV/AIDS as an emerging threat that the nearly non-existent health infrastructure in most isolated mining areas is not equipped to handle. Close quarters and hard labour mean that other health issues, including physical trauma, diarrhoea, tuberculosis, respiratory infections, malnutrition and malaria, are rampant. It is certainly plausible that HIV/AIDS and other sexually transmitted infections (STIs) may be more prevalent in mining towns in the eastern DRC, as is the case in other settings (Clift et al. 2003; Conro and Walque 2012). Furthermore, superstition often replaces education about the spread of disease, increasing the likelihood of high STI prevalence rates in ASM communities (Pact Inc. 2010). Populations working in and around mines are at risk of a great number of other health risks due to structural issues, exposure to minerals, ergonomic concerns and a lack of sanitation and safety equipment. Health issues include, but are not limited to, mining disasters, mercury exposure, radioactive material exposure, gastrointestinal disease, malnutrition, infection, lung disease, bone and muscle injuries and heat stress (Walle and Jennings 2001; Hayes and Wauwe 2009; Pact Inc. 2010; Kelly et al. 2014a). Pregnancy, reproductive problems and injuries due to SGBV are also issues of concern for women specifically, especially given the general lack of access to adequate health care (Pact Inc. 2010; Hayes and Perks 2012). Drug and alcohol abuse is described as being rampant in mining towns and inside the quarries themselves. Substance abuse has led to an increase in violence and a breakdown in the social fabric of their villages.

Of those who needed health care in the past year, a majority of respondents from Phase 2 said they accessed it and thought the care they received was adequate. Women, however, were three times more likely to say that the care they received was not adequate. This potentially speaks to the health system being ill prepared to provide for the health care needs of women, which includes unintended pregnancy, sexual and physical violence and STIs. Women also reported health facilities as being unable to treat their conditions more than men did. Cost was cited as a barrier to care, with 
14 per cent of women and 7 per cent of men saying they had been denied medical care at least once in their lives, often because they could not pay. Those in the most vulnerable and lowest-paying jobs were the most likely to be denied care. This is an especially concerning issue because those most likely to report being denied care are also the most likely to report having had a health problem in the past year. Although those who have health problems may experience more denial of care because they seek care more often, these results speak to the fact that those in the least privileged jobs are the most likely to have health issues. A quarter of the respondents said they had taken loans to pay for medical care. In the USAID study conducted in mining towns in South Kivu and Maniema, paying for health care was cited as the third-most common reason that people took loans (Kelly et al. 2014a).

Against this challenging backdrop, however, the research pointed to promising examples of civic organisations with the potential for providing inclusivity and social support to miners. According to the DRCMining Code, all artisanal miners are obliged to be part of a cooperative. The experience of cooperative formations in ASM in the DRC is, however, extremely varied. Members pay a range of entrance fees and taxes. Depending on the size and scope of the cooperative, miners may either enjoy profit-sharing arrangements and protection, or receive no such benefits (Pact Inc. 2010). Although hailed by the government as critical for better organising ASM, the perception of cooperatives' benefits for miners varies. For instance, Kelly (2014) reported that certain mining communities perceive cooperatives as being embedded within the hierarchy and failing to represent many within the community. Geenen (2014) expresses a similar concern, specifically in the gold mines of South Kivu.

Yet, the power of a collective organisation as a means to represent miners' concerns and respond to immediate issues cannot be altogether dismissed. The research results from this project suggest that smaller, trade-specific groups known as associations may be more beneficial for marginalised communities, thereby supporting prior research in specific mining areas. For instance, a USAID survey found that less than 20 per cent of workers in the lowest-paying trades, such as potters, food venders and sex workers, reported belonging to a community group, compared to 50 per cent of mining team leaders and 25 per cent of miners (Kelly et al. 2014a). Additionally, 25 per cent of men reported belonging to groups, compared with 17 per cent of women (ibid.). For instance, in select areas of northern Orientale, associations that combine literacy and savings objectives for 
miners have proven to be effective vehicles for self-organisation (Hayes and Wauwe 2009). Meanwhile in South Kivu (Kelly et al. 2014a), there is the example of the Association of Free Women, representing women involved in sex work. Members of the group expressed the critical role it has played in their access to health care, financial stability and social support. In Phase 2, women surveyed reported greater access to savings and loan programs than men, possibly because non-government organisations target women for these programs. Utilisation of these services, however, was extremely low ( 9 per cent for women and 6 per cent for men), despite the fact that half of all women and three-quarters of men stated they wanted access to these programs, indicating a large unmet need. Such forms of self-organisation described earlier could be better expanded.

Indeed, in the absence of courts and tribunals, as well as capable national human rights institutions or ombudspersons, participants in the research said they relied on each other and small associations as the most neutral and capable parties for bringing some level of justice in their communities. Active systems of association were in fact present at every site, speaking of an enterprising spirit and a desire for more inclusive political engagement. People often self-organised to promote a common profession, cause or interest. However, these groups lack the financial means, human capacity and political influence to make sustainable change. Organising to create more effective unions and associations, while promoting grassroots inclusive economic cooperatives, offers a potentially more meaningful opportunity for improving life in mining towns.

The implementation of laws and policies is a critical part of the formalisation process for artisanal mining in the DRC. Knowledge of and adherence to these laws at the local level is the only avenue for successful implementation. A minority of men and women surveyed, however, stated that they were aware of the existence of the mining code and of related laws. Women were far less likely than men to report knowledge of the mining code. Community organisations were described as an effective avenue for education for all members of the community. There were, however, gendered differences in ways that people gained knowledge. Men were most likely to receive information from radio messages, whereas women stated they received information more readily from their peers.

Findings from this work bring to light several new pathways for understanding the challenges facing both men and women in the mines of the eastern DRC. These pathways also emphasise the need for holistic 
responses to ensure sufficient change in behaviours and practices in the mines of the DRC. These programmatic and policy responses will need to be fundamentally linked to the long-term project of rebuilding the state in the DRC. Most importantly, reforms should be informed by, and responsive to, the needs of those working in mining, so that all of those seeking fair and equitable work opportunities can find them.

\section{References}

Autesserre, S., 2012. 'Dangerous Tales: Dominant Narratives on the Congo and their Unintended Consequences.' African Affairs 111(443): 202-22. doi.org/10.1093/afraf/adr080

Banchirigah, S.M., 2008. 'Challenges with Eradicating Illegal Mining in Ghana: A Perspective from the Grassroots.' Resources Policy, 33(1), 29-38. doi.org/10.1016/j.resourpol.2007.11.001

Bashwira, M.R., J. Cuvelier, D. Hilhorst and G. van der Harr, 2014. 'Not Only a Man's World: Women's Involvement in Artisanal Mining in Eastern DRC.' Resources Policy 40: 109-16. doi.org/10.1016/j. resourpol.2013.11.002

Bryceson, D.F. and J.B. Jønsson, 2010. 'Gold-Digging Careers in Rural East Africa: Small-Scale Miners Livelihood Choices.' World Development 38(3): 379-92. doi.org/10.1016/j.worlddev.2009.09.003

Clift, S., A. Anemona, D. Watson-Jones, Z. Kanga, L. Ndeki, J. Changalunch, A. Gavyole and D.A. Ross, 2003. 'Variations of HIV and STI Prevalences within Communities Neighbouring New Goldmines in Tanzania: Importance for Intervention Design.' Sexually Transmitted Infections 79: 307-12. doi.org/10.1136/ sti.79.4.307

Conro, L. and D. Walque, 2012. 'Mines, Migration and HIV/AIDS in South Africa.' Journal of African Economics 21(3): 465-98. doi. org/10.1093/jae/ejs005

Eftimie, A., K. Heller, J. Strongman, J. Hinton, K. Lahiri-Dutt, N. Mutemeri, C. Insouvanh, M. Godet Sambo and S. Wagner, 2012. Gender Dimensions of Artisanal and Small-Scale Mining: 
A Rapid Assessment Tool. Washington, DC: World Bank Group's Oil, Gas and Mining Unit. Available at siteresources.worldbank.org/ INTEXTINDWOM/Resources/Gender_and_ASM_Toolkit.pdf

Geenen, S., 2012. 'A Dangerous Bet: The Challenges of Formalizing Artisanal Mining in the Democratic Republic of Congo.' Resources Policy 37(3): 322-30. doi.org/10.1016/j.resourpol.2012.02.004

Geenen, S., 2014. 'Dispossession, Displacement and Resistance: Artisanal Miners in a Gold Concession in South Kivu, Democratic Republic of Congo.' Resources Policy 40: 90-9. doi.org/10.1016/j. resourpol.2013.03.004

Geenen, S. and S.R. Custers, 2010. 'Tiraillements Autour du Secteur Minier de l'Est de la RDC.S.' L'Afriique Des Grands Lacs. Annuaire 2009-2010, Paris, pp. 231-58.

Hayes, K. (ed.), 2008. '2008 Regional Workshop: Small-Scale Mining in Africa: A Case for Sustainable Livelihood.' Amsterdam: Commonwealth Fund for Commodities.

Hayes, K. and R. Perks, 2012. 'Women in the Artisanal and Small-Scale Mining Sector of the Democratic Republic of the Congo.' In P. Lujala and S.A. Rustad (eds), High-Value Natural Resources and Peacebuilding. Oxon and New York: Earthscan.

Hayes, K. and V. Wauwe, 2009. Microfinance in Artisanal and SmallScale Mining.' Background Papers for 9th Annual CASM Meeting. Maputo, MZ: Communities and Small-Scale Mining.

Hilson, G., 2009. 'Small-Scale Mining, Poverty and Economic Development in Sub-Saharan Africa: An Overview.' Resources Policy 34(1-2): 1-5. doi.org/10.1016/j.resourpol.2008.12.001

Hilson, G., 2011. 'Artisanal Mining, Smallholder Farming and Livelihood Diversification in Rural Sub-Saharan Africa: An Introduction.' In G. Hilson and M. Hirons (eds), Artisanal Mining, Smallholder Farming and Economic Development in Rural Sub-Saharan Africa. Special Issue of Journal of International Development 23(8): 1031-41. doi.org/10.1002/jid.1829 
Hinton, J., M. Veiga and C. Beinhoff, 2003. 'Women and Artisanal Mining: Gender Roles and the Road Ahead.' In G. Hilson (ed.), Socioeconomic Impacts of Artisanal and Small-Scale Mining in Developing Countries. Netherlands: Swets \& Zeitlinger B.V. Publishers. doi. org/10.1201/9780203971284.ch11

Kelly, J., 2014. “"This Mine has become our Farmland”: Critical Perspectives on the Coevolution of Artisanal Mining and Conflict in the Democratic Republic of the Congo.' Resources Policy 40: 100-8. doi.org/10.1016/j.resourpol.2013.12.003

Kelly, J., N. Greenberg, D. Sabet and J. Fulp (eds), 2014a. 'Assessment of Human Trafficking on Artisanal Mining Towns in Eastern Democratic Republic of the Congo.' Arlington: US Agency for International Development and Social Impact, Inc.

Kelly, J., T. King-Close and R. Perks, 2014b. 'Resources and Resourcefulness: Roles, Opportunities and Risks for Women Working at Artisanal Mines in South Kivu, Democratic Republic of the Congo.' Futures 62A: 95-105. doi.org/10.1016/j.futures.2014.04.003

Lahiri-Dutt, K. and M. Macintyre, 2006. Women Miners in Developing Countries: Pit Women and Others. London: Ashgate.

Luning, S., 2008. 'Liberalisation of the Gold Mining Sector in Burkina Faso.' Review of African Political Economy 35(117): 387-401. doi. org/10.1080/03056240802411016

Maconachie, R. and J.A. Binns, 2010. 'Farming Miners or Mining Farmers? Diamond Mining and Rural Development in PostConflict Sierra Leone.' Journal of Rural Studies 23(3): 367-80. doi. org/10.1016/j.jrurstud.2007.01.003

Mahy, P.K., 2012. Gender Equality and Corporate Social Responsibility in Mining: An investigation of the Potential for Change at Kaltim Prima Coal, Indonesia. The Australian National University (PhD thesis).

Pact Inc., 2010. PROMINES Study: Artisanal Mining in the Democratic Republic of Congo. Washington, Congo and Kinshasa: Pact Inc.

Perks, R., 2011. 'Can I Go? Exiting the Artisanal Mining Sector in the Democratic Republic of the Congo.' Journal of International Development 23(8): 115-27. doi.org/10.1002/jid.1835 
Perks, R., 2013. 'Digging into the Past: Critical Reflections on Rwanda's Pursuit for a Domestic Mineral Economy.' Journal of East African Studies 7(4): 732-50. doi.org/10.1080/17531055.2013.841025

Seay, L., 2012. 'What's Wrong with Dodd-Frank 1502? Conflict Minerals, Civilian Livelihoods, and the Unintended Consequences of Western Advocacy.' Working Paper 284. Center for Global Development.

Seay, L., 2014. 'Did Cutting Access to Mineral Wealth Reduce Violence in the DRC?' The Washington Post, 25 March. Available at www. washingtonpost.com/news/monkey-cage/wp/2014/03/25/didcutting-access-to-mineral-wealth-reduce-violence-in-the-drcl

Smith, J., 2011. 'Tantalus in the Digital Age: Coltan, Ore, Temporal Dispossession, and Movement in the Eastern Democratic Republic of the Congo.' Journal of the American Ethnological Society 38(1): 17-35. doi.org/10.1111/j.1548-1425.2010.01289.x

Spittaels, H. and F. Hilgert, 2013. 'Analysis of the Interactive Map of Artisanal Mining Areas in Eastern DR Congo.' Viewed at ipisresearch. be/publication/analysis-interactive-map-artisanal-mining-areaseastern-dr-congo/

Walle, M. and N. Jennings, 2001. 'Safety and Health in Small-Scale Surface Mines: A Handbook.' Working Paper No. 168. Sectoral Activities Program. Geneva: International Labour Organization.

World Bank, 2015a. 'Resources and Resourcefulness: Gender, Conflict, and Artisanal Mining Communities in Eastern Democratic Republic of the Congo.' Working Paper 95971. Washington, DC: World Bank Group. Available at documents.worldbank.org/curated/en/2015/ 04/24418255/resources-resourcefulness-gender-conflict-artisanalmining-communities-eastern-democratic-republic-congo

World Bank, 2015b. 'Empowering Women in the Mines of the Eastern Democratic Republic of the Congo.' 30 April. Washington, DC: World Bank. Available at www.worldbank.org/en/news/feature/2015/05/04/ empowering-women-in-the-mines-of-the-eastern-democraticrepublic-of-the-congo?cid=ISG_E_WBWeeklyUpdate_NL 
This text is taken from Between the Plough and the Pick: Informal, artisanal and small-scale mining in the contemporary world, edited by Kuntala Lahiri-Dutt, published 2018 by ANU Press, The Australian National University, Canberra, Australia.

doi.org/10.22459/BPP.03.2018.10 